\title{
CONSEQUENCES OF HOLOCAUST ON PHYSICAL HEALTH OF SURVIVORS: BIBLIOGRAPHY REVIEW
}

\author{
Kateřina Horáčková', Andrea Ševčovičová2, Zdeněk Hrstka', Markéta Moravcová1, Martina Lásková2 L'ubica \\ Derňarová ${ }^{3}$ \\ ${ }^{1}$ Faculty of Health Studies, Pardubice University, Pardubice, Czech Republic \\ ${ }^{2}$ St. Elisabeth University of Health Care and Social Work, Bratislava, Slovak Republic \\ ${ }^{3}$ Faculty of Health Care, University of Prešov, Prešov, Slovak Republic
}

\section{SUMMARY}

Objective: Period of elderly age preordains the occurrence of many health issues. People deported during World War II to concentration camps suffered from malnutrition, lack of sleep, physical and mental exhaustion. Recently, the health condition of Holocaust survivors is often complicated as a result of physical punishments and different torture methods as well as mental hardships which they had suffered during deportation. The consequences often have psychosomatic nature thus the survivors are often receivers of health care. The topic of bibliography review is based on the need to objectivize and systematically evaluate subjective health issues of Holocaust survivors in connection with trauma related to the stay in a concentration camp. The aim is to offer a review of effects of the Holocaust on health of different body systems for survivors in concentration camps and Jewish ghettos in the course of World War II.

Methods: To map the subjective problems of Holocaust survivors, evidence-based medicine (EBM) method has been used with the help of scientific database PubMed, CINAHL Plus with full text, ProQuest and other sources with specific key words and Boole operators. Prognostic type of clinical/review questions has been selected for the bibliography review, which is trying to predict the probability of relation or output of illness/ condition and based on diseases or symptoms seriousness to find out expectancy for treatment/improvement of care.

Results: 175 studies have been found in basic search with the use of key words both in English and in Czech language. The search has not been time-limited. The advanced search has focused on different body systems and health damage due to Nazi experiments. Fourteen studies have been used to complete the study. The research results have confirmed the significant effect of Holocaust trauma on body condition of the survivors. The reasons of this condition were insufficient nutrition, unsuitable and harmful hygienic, living and working conditions and brutality of the guards. According to the research, these factors have impacted all organ systems, mainly locomotion and cardiovascular ones. The results have shown a more frequent occurrence of osteoporosis, fractures of long bones and corresponding chronical pain of people of Jewish origin who had gone through different forms of torture during World War II. Other present symptoms include gastrointestinal problems, tumors mainly in the area of colorectum and lungs. Moreover, the stay in concentration camps had influence on women's menstrual cycle.

Conclusion: The studies of Holocaust effects are an example of the influence of an extreme mental and physical burden on the body condition of the survivors' health. The results of the studies have shown a wide range of the effects also in mental and social areas.

Key words: Holocaust, concentration camp, illness, interned people, patient, health care

Address for correspondence: K. Horáčková, Faculty of Health Studies, Department of Nursing, Průmyslová 395, 53210 Pardubice, Czech Republic. E-mail: katerina.horackova@upce.cz

https://doi.org/10.21101/cejph.a5650

\section{INTRODUCTION}

During World War II, the Jews suffered from ongoing health issues, malnutrition, and constant psychical pressure during their forced stay in shelters, ghettos and concentration camps. Although more than 70 years passed from World War II, there are still last survivors among us, who belong to the specific group of seniors $(1,2)$.

Elderly age predicts the occurrence of many health issues itself and includes specific symptomatology (3). With Holocaust survivors, the physical condition is often complicated by the effects of torture (e.g. physical punishments, long standing in frost and rain, etc.) as well as mental hardship which they had to undergo during the Holocaust. The effects of this hardship are displayed in the survivors in all elements of their personalities and very often they are of psychosomatic nature. This is why the survivors are often receivers of institutional care, mainly health care (4).

The topic of this literature search is based on the need to objectivize and systematically evaluate subjective health issues of Holocaust survivors which are related to the trauma experienced in World War II. Holocaust trauma has influenced the health of the survivors in biological, social, psychological, and spiritual contexts. It is necessary to pay attention to all those areas as they are related and influence each other. However, this is a very wide area and therefore this is the reason why the following text is devoted only to the somatic area. 


\section{MATERIALS AND METHODS}

\section{Review Question}

Table 1 presents the eliminative and including criteria which have been determined for the different parts of the elaborated review question (search questions).

Prognostic type of clinical/review question has been selected for the chosen literary search. Such type of question tries to predict the probability of relation or output of the illness/condition and to find out the perspective of recovery/care improvement on the base of illness seriousness or symptoms (5).

Did the conditions during the Holocaust (life in shelter, Jewish ghetto and concentration camp) influence (I) physical health (O) of Holocaust survivors $(\mathrm{P})$ ?

\section{Searching Strategies}

It has been essential to choose so-called three-degree strategy to achieve valid conclusions.

1) Degree of search: basic search - PubMed and CINAHL Plus with full text citation databases have been used for the basic search which are freely available and into which basic key words and their variants have been inserted with the use of Boole operators AND and OR (Table 2). Localisation operators have not been used in the search. The search has not been limited in time, but it has been limited to English and Czech language.

2) Degree of search: advanced search - from the focus of searched studies within the basic degree of the search it has been clear that the life in internment institutions during World War II, including the life in the shelter, had impact on the most of body (organ) systems. Therefore, the advanced search has focused on different body systems. Key words have also been selected according to that. The method of search is the same as the basic level including the use of Boole operators. Key words and the number of searched studies are shown in PRISMA protocol in Figure 1.

3) Degree of search: at this stage the authors manually checked their reference lists of relevant studies to determine whether any relevant work was overlooked or found. Given the historical context of the research problem, the authors also focused on grey literature using the ProQuest scientific database. The search strategy was the same as in the previous stages. According to experts in the field, books have been included in

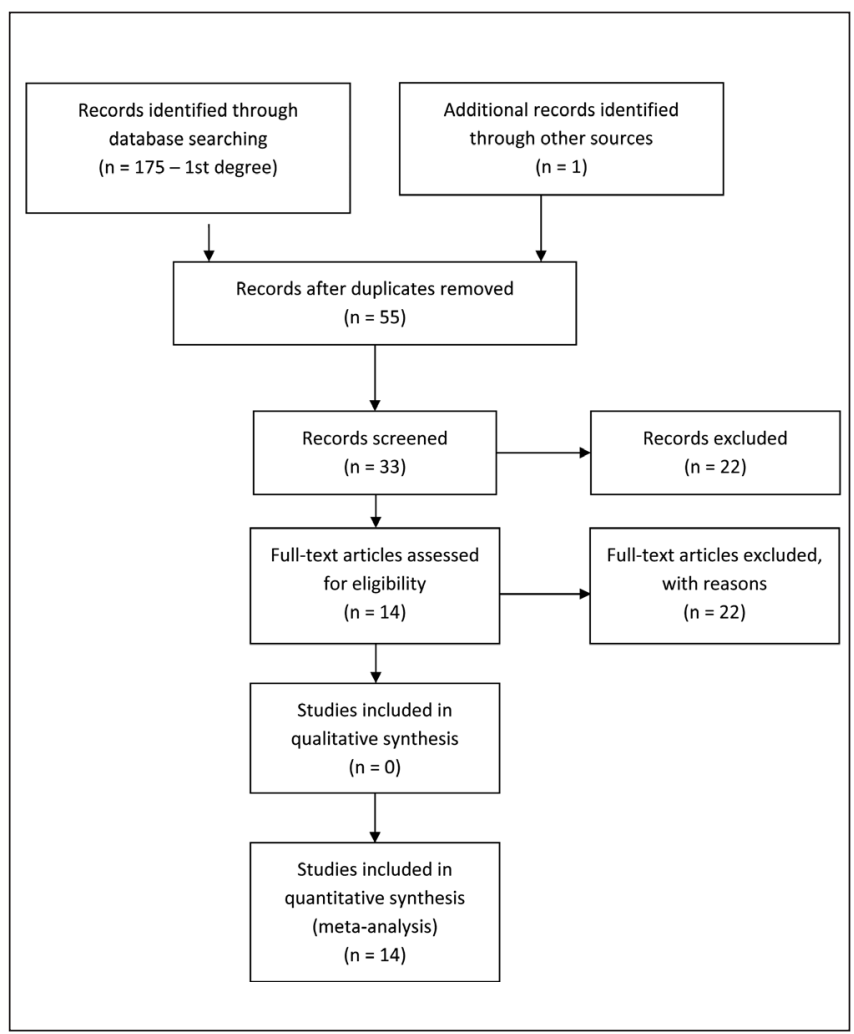

Fig. 1. PRISMA diagram.

Table 1. Exclusion and inclusion criteria to research question

\begin{tabular}{|l|l|}
\hline PICO & Exclusion and inclusion criteria \\
\hline Patient (P) & $\begin{array}{l}\text { "Survivor" according to Barša (36) definition - a Jew who lived in period } 1933 \text { to } 1945 \text { in some internment institution } \\
\text { in Europe or emigrated as a result of occupation or deportation declaration (emigrants, active fighters, concentration } \\
\text { camp prisoners, and children in hiding). }\end{array}$ \\
\hline Intervention (I) & Influence of living conditions (Jewish ghetto, concentration camp, shelter) in the Holocaust period. \\
\hline Comparison (C) & Not used. \\
\hline Output (O) & Body dimension of survivors' health. \\
\hline Study & Retrospective, cohort, cross-sectional and longitudinal study, case and control study. \\
\hline
\end{tabular}

Source: own adaptation, 2018

Table 2. Associated key words to research question - basic search

\begin{tabular}{|c|c|c|c|}
\hline \multicolumn{4}{|c|}{ Key words to research question } \\
\hline Patient $(P)$ & Intervention (I) & Comparison (C) & Output (0) \\
\hline Holocaust & Ghetto & - & Quality of life \\
\hline Survivor & Concentration camp & - & Health \\
\hline Prisoner & Hiding & - & Disease \\
\hline
\end{tabular}

Source: own adaptation, 2018 
the review too. A number of searched studies and books are shown in PRISMA protocol in Figure 1.

\section{Selection and Analysis of Studies}

The searched studies have been eliminated according to the recommendation of PRISMA (6). The found evidence was evaluated based on the hierarchy of the evidence level according to Fineout-Overholt and Johnston (7), who classify them into seven categories. The level III evidence was included in the present study (evidence gained at least from one well-processed randomised control study), the level IV evidence (the evidence gained from well-processed non-randomised control study and from well-processed case study and cohort study), and the level VI evidence (the evidence from one descriptive or quality study) (7). 175 studies in the databases have been found in the 1st degree of search. In the 2 nd degree of search 83 studies and 1 conference paper have been found. The duplicate studies, the survivors' memories and theoretical studies have been eliminated; 14 studies have been used to complete the study.

\section{RESULTS AND DISCUSSION}

The relation between the Holocaust trauma and physical health of the survivors has already been the subject of research in the past, however, not by researchers from the countries of so-called Eastern block (Czechia, Slovakia, Poland, and Hungary). The interest of the researchers has only been seen in the countries with high percentage of survivors, i.e. places where a large part of the survivors immigrated during the war or after that and where they have lived or live until now (USA, Israel, Australia) in the end of the 20th century.

It is obvious from the search that Holocaust trauma has directly influenced the survivors' physical condition. Among the main reasons for those effects are insufficient nutrition, ever-present stress, completely inadequate and harmful hygienic, life and working conditions and guard brutality. Finally, it is critical to mitigate the impacts on the survivor health resulting from cruel and unethical Nazi medical experiments, that were conducted mostly on Jewish prisoners in concentration camps in the area occupied by Nazis. According to the researches, those factors have hit all organ systems, mainly motoric and cardiovascular systems. The following text presents the implications in different organ systems found in the researched publications.

The researches of authors who have been working with the issue for long time have been selected to the data presentation. They are the specialists from world centres for Holocaust research.

Results are presented in Table 3 - 13 quantitative studies and 1 bibliography review that examined the Holocaust trauma influence on the survivors' health. Selected studies evaluated the selected area of diseases only. None of the studies evaluated complex influence on survivors' health from the bio-psychosocio-spiritual view. The researches mostly focused on the study of relations between Holocaust surviving and occurrence of selected civilization diseases (osteoporosis, tumor diseases, obesity, diabetes mellitus, hypertension, stomach ulcer, etc.). The common measure of most of the researchers was the verification of hypothesis whether nutrition and environmental condition at embryonal, foetal, neonatal and child age have influence on the development of these diseases in survivors in late adult age. For the discussion several scientific historic studies published in scientific magazines or books were used.

Long-term malnutrition effects on the human growth have been known longer, and these effects were secretly studied by 28 Jewish doctors in Warsaw ghetto, led by Dr. Israel Milezkowski. The doctors determined the diagnosis "hungry disease" for all patients who consumed less than 800 calories a day and did not show any signs of other diseases. The researchers observed circulation and metabolic changes in bodies of adult patients developed as a result of starving, as well as they observed body response to renewed intake of food. All patients identically displayed changes in physiological functions (hypotension, hypothermia, bradycardia, bradypnoe), they suffered from grey cataract and metabolic dysfunctions (osteopenia, osteoporosis, glycogen depletion, and loss of muscles) $(8,9)$.

The results of nowadays studies identically represent the Jewish population of survivors as a population with significantly higher prevalence of osteoporosis and osteopenia (mostly women), and they point to frequent coxae fracture, problematic rehabilitation with consequent disability development, loss of independence, and development of further problems in the biopsycho-social-spiritual context (10-13). The other appearing phenomenon is a chronic pain, although this is not perceived as a significant problem by the survivors, since they have adapted to it. The authors identically describe causes of these conditions, and that is mostly the influence of starving on foetal programming, and so the development of metabolic syndrome and bone demineralization. Among other causes, there are hormonal changes, stress, hard work, and torturing considered $(14,15)$.

The study of Holocaust survivors further points to the relation between foetal programming and higher occurrence of diseases and presence of risk factors, such as obesity, dyslipidemia, diabetes mellitus, hypertension, cardiovascular morbidity, malignity (mostly higher occurrence of tumors in the area of colorectum in both sexes, breast in women, and lungs in men), and chronic function gastrointestinal symptomatology (abdominal pains, irregular intestines habits, diarrhoea, constipation, abdominal distension, pyrosis, flatulency, anorexia, nausea, vomiting, mucus in stool, tenesmus, aerophagia) with more frequent occurrence in women. The influence of mentioned factors on survivors' oral health has also been documented. (16-22).

The last stated area of researchers' interest is a reproduction system of survived women, mainly the influence of stay in German internment facilities on menorrheal cycle, fertility, and women gynaecological diseases. The study proves the internment influence on sudden changes in short-term menorrheal function in the period of internment, though it does not support the longterm physical damage of reproduction function. Regarding what has been mentioned, it is necessary to state the fact that female respondents during their internment were not a part of any research experiments, nor underwent gynaecological intervention in the time of their internment (23).

Mostly experimental sterilizations of men and women were applicated as the preparation for biological cleansing of Slavic nations, and experiments with in vitro fertilization and infertility treatment. Experiments on twins with aim of quick reproduction of the German race, and experiments with the patients of dwarfism 


\begin{tabular}{|c|c|c|c|c|c|c|c|c|c|}
\hline & 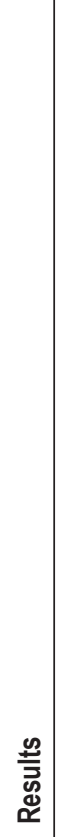 & 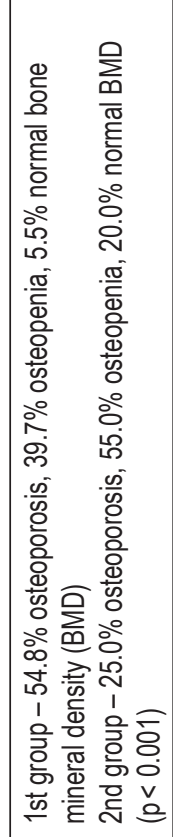 & 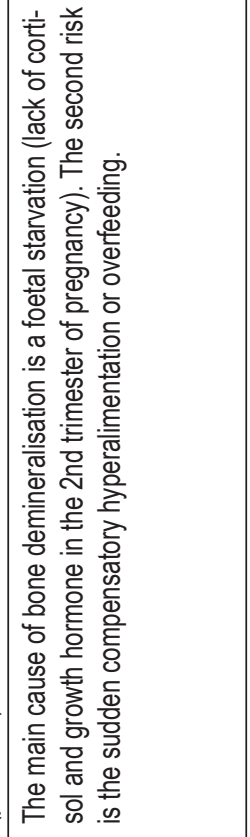 & 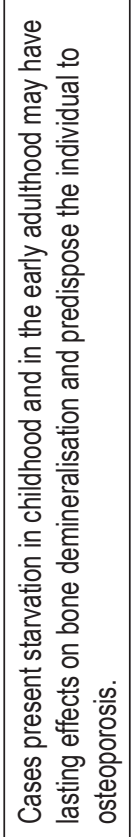 & 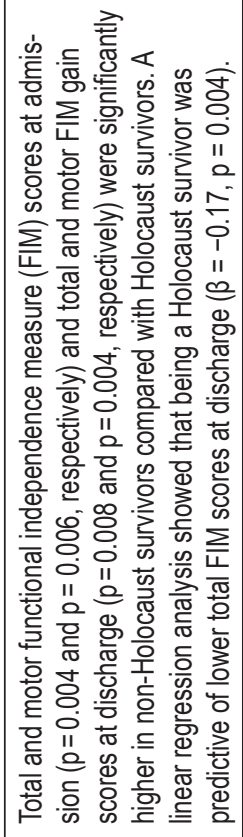 & 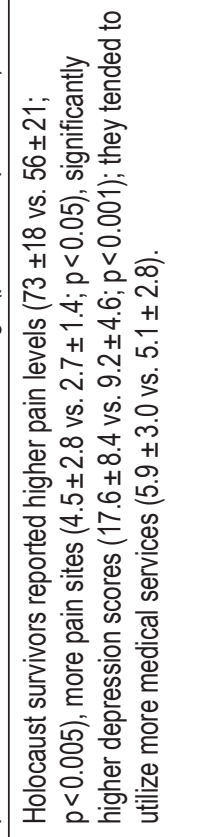 & 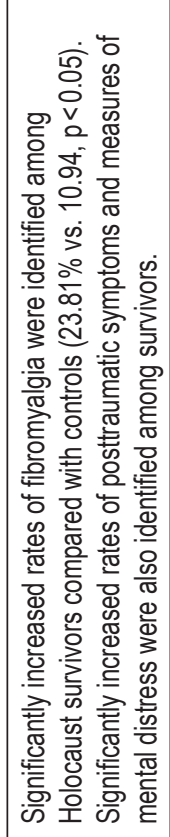 & 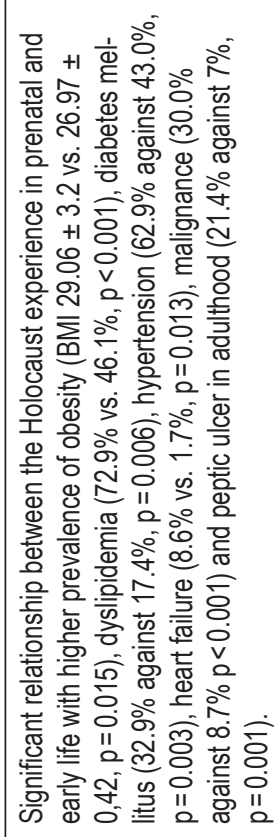 & 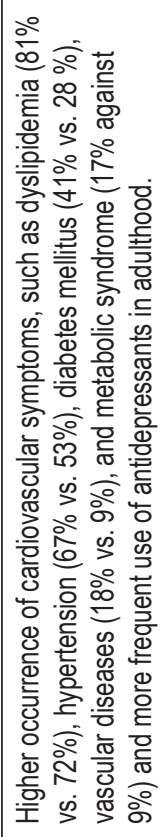 \\
\hline & 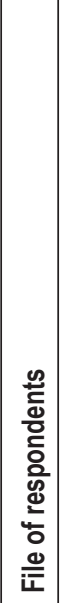 & 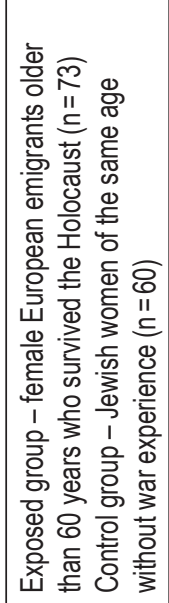 & 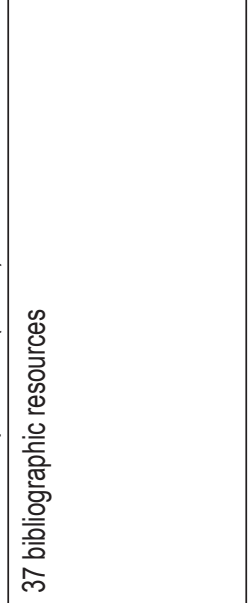 & 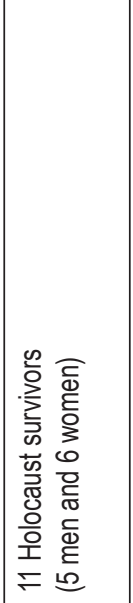 & 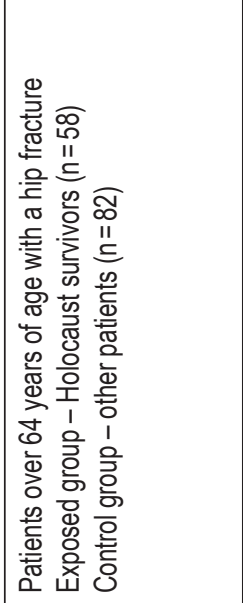 & 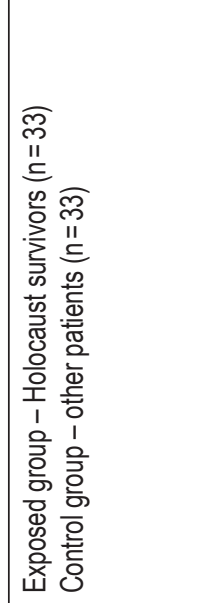 & 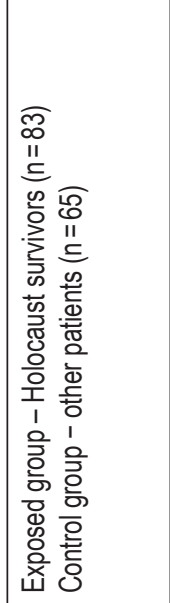 & 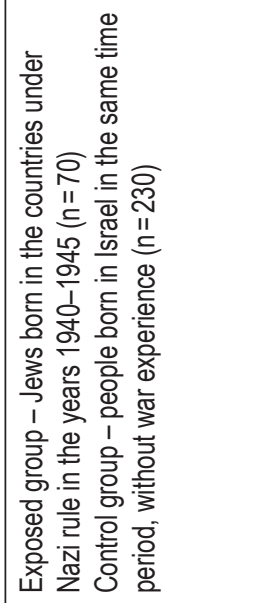 & 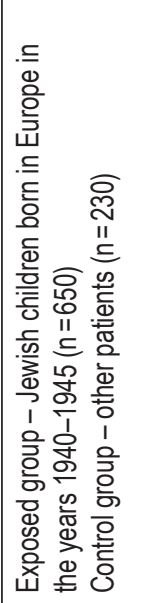 \\
\hline & 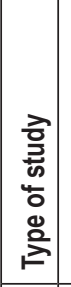 & 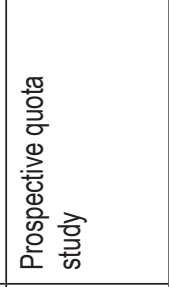 & 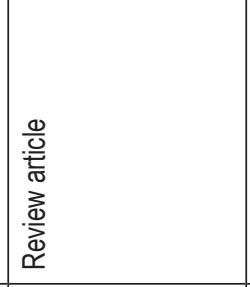 & 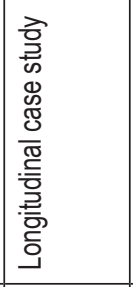 & 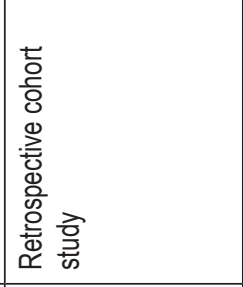 & 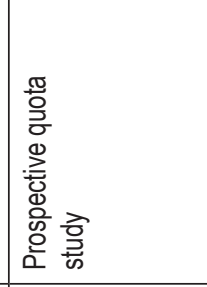 & 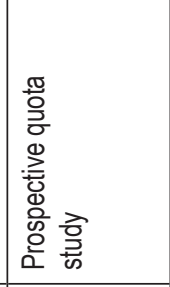 & 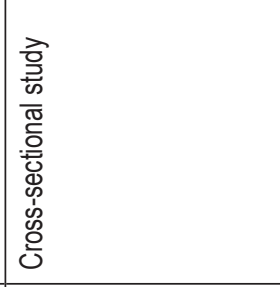 & 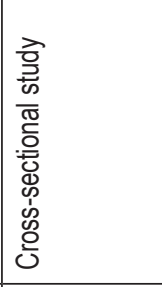 \\
\hline & 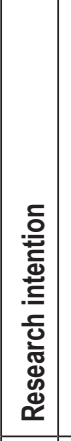 & 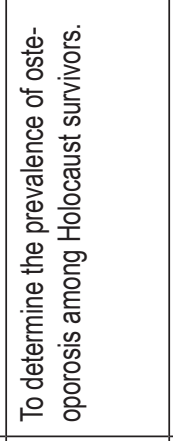 & 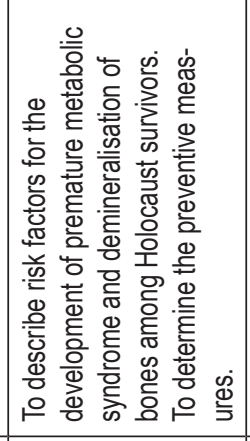 & 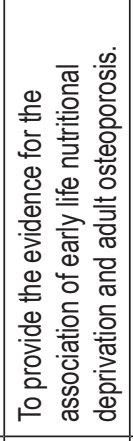 & 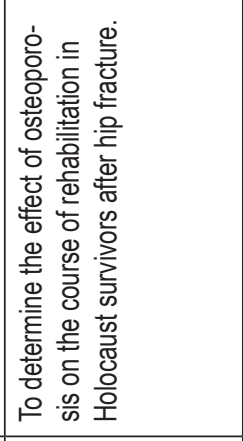 & 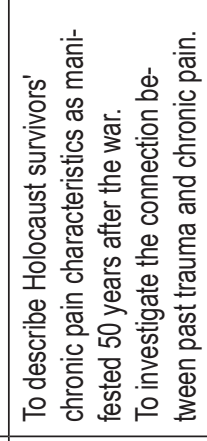 & 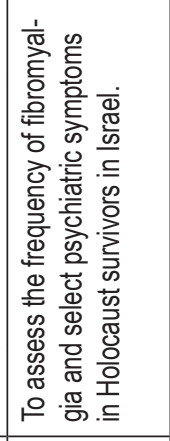 & 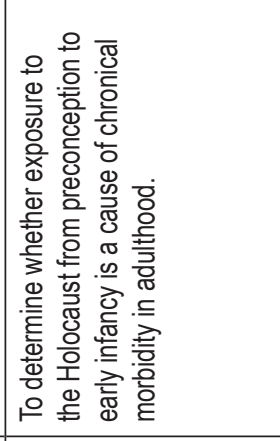 & 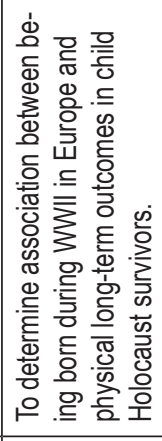 \\
\hline & 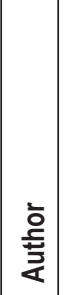 & 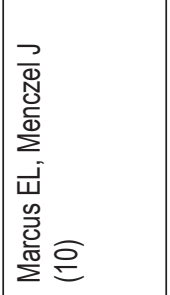 & 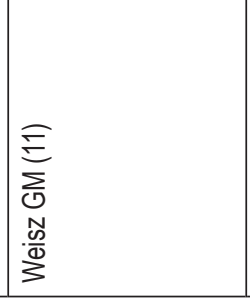 & 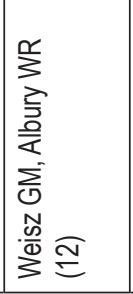 & 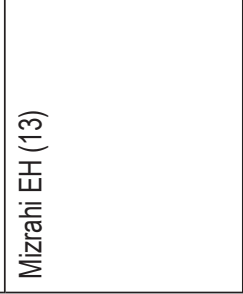 & 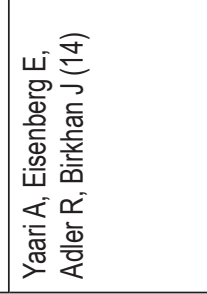 & 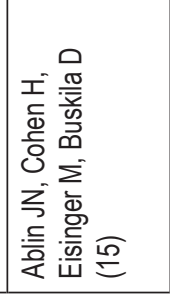 & 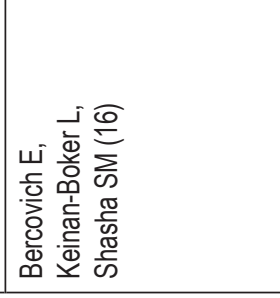 & 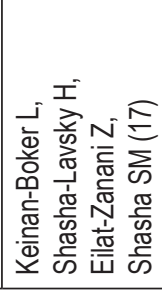 \\
\hline
\end{tabular}




\begin{tabular}{|c|c|c|c|c|c|}
\hline 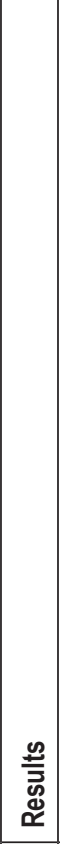 & 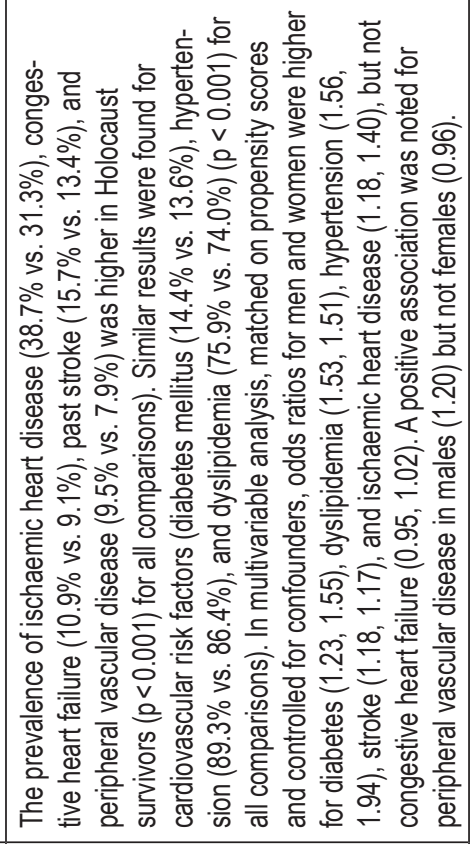 & 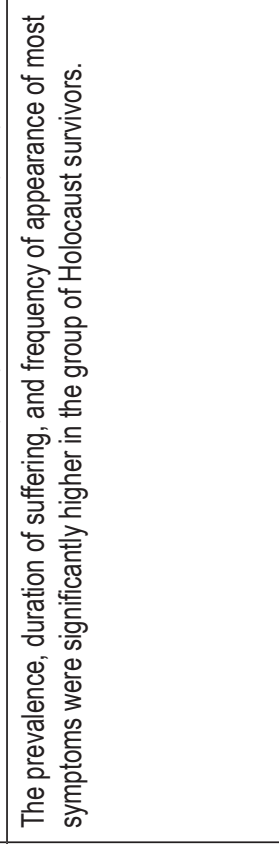 & 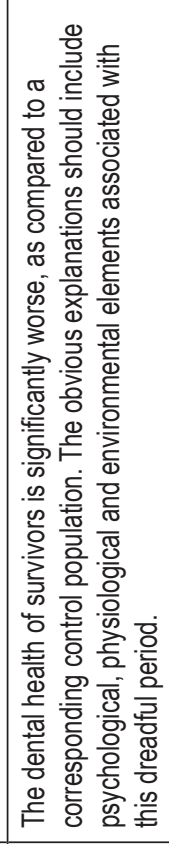 & 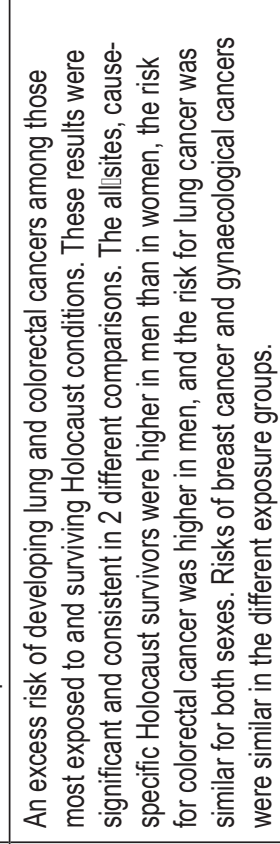 & 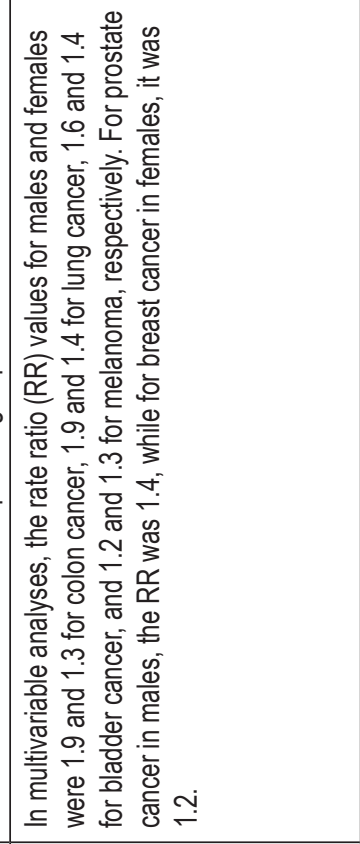 \\
\hline 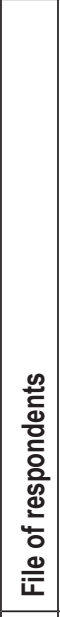 & 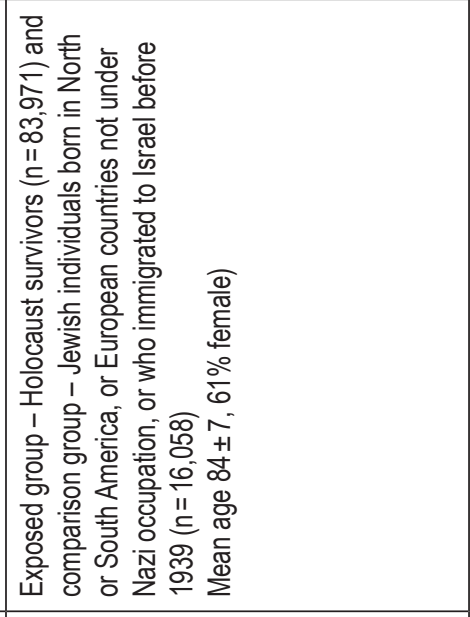 & 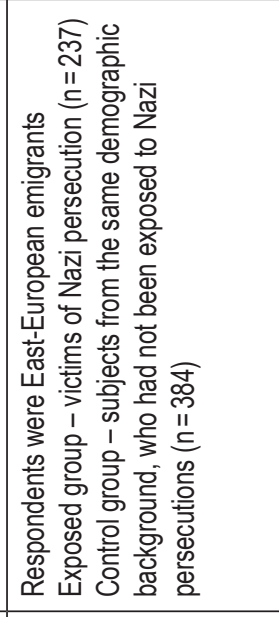 & 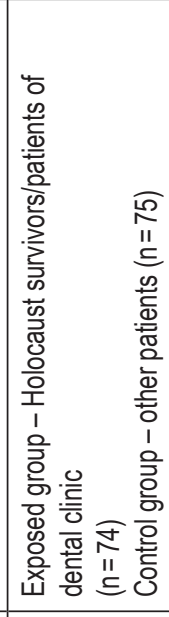 & 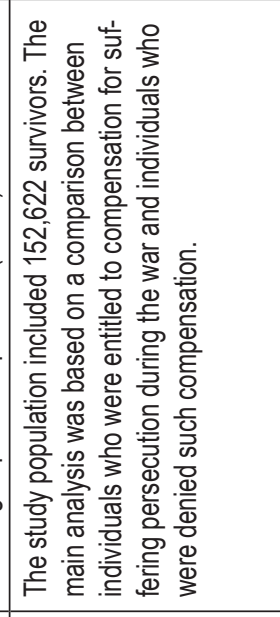 & 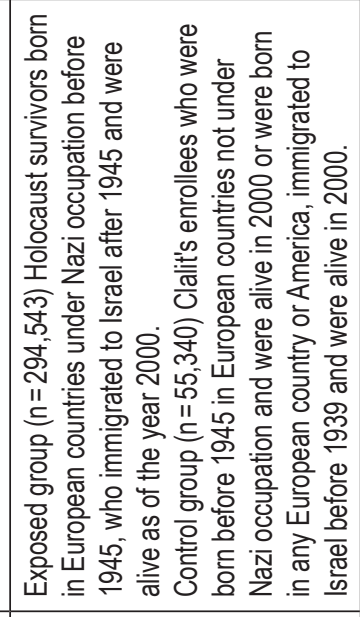 \\
\hline 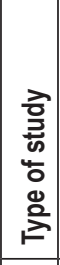 & 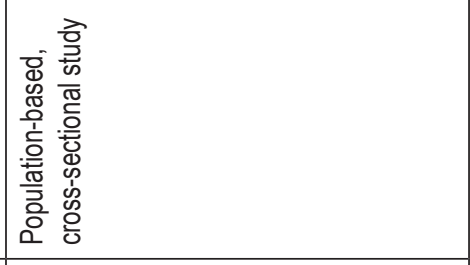 & 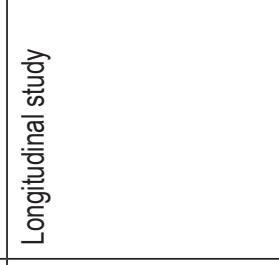 & 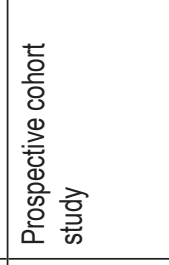 & 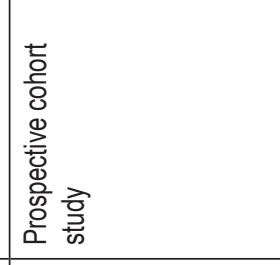 & 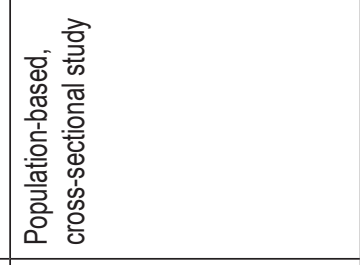 \\
\hline 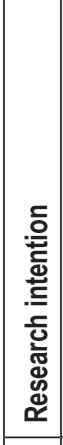 & 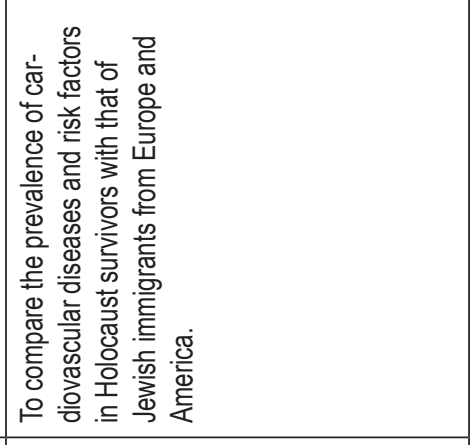 & 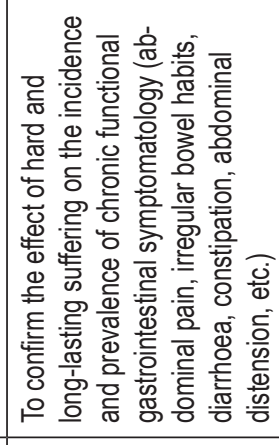 & 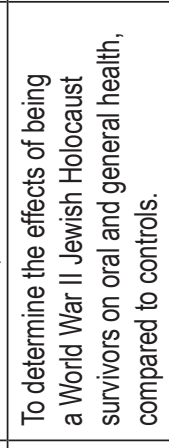 & 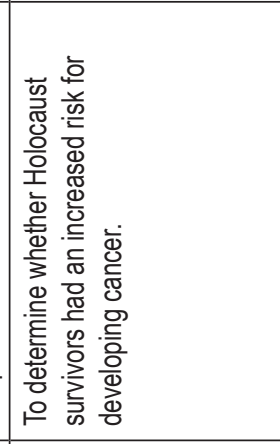 & 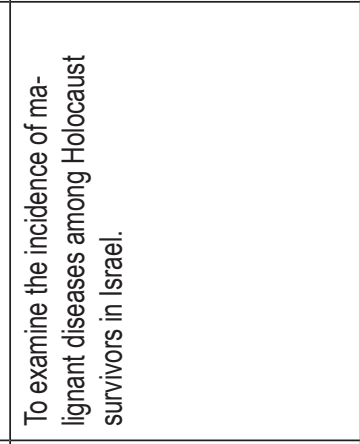 \\
\hline 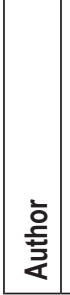 & 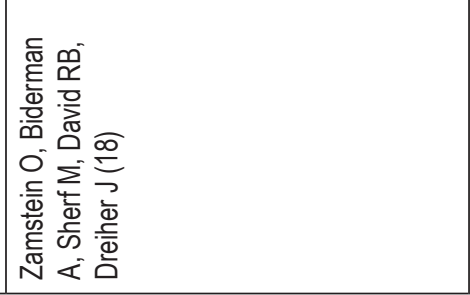 & 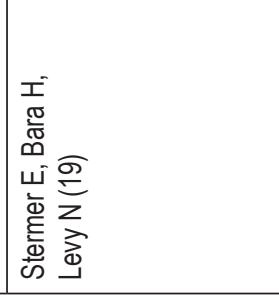 & 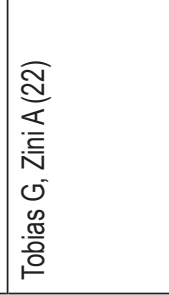 & 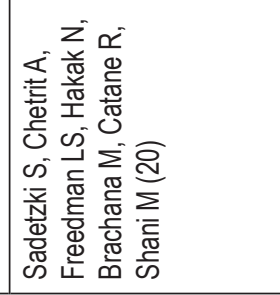 & 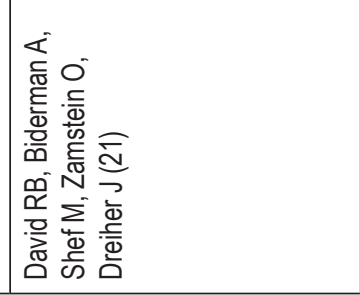 \\
\hline
\end{tabular}




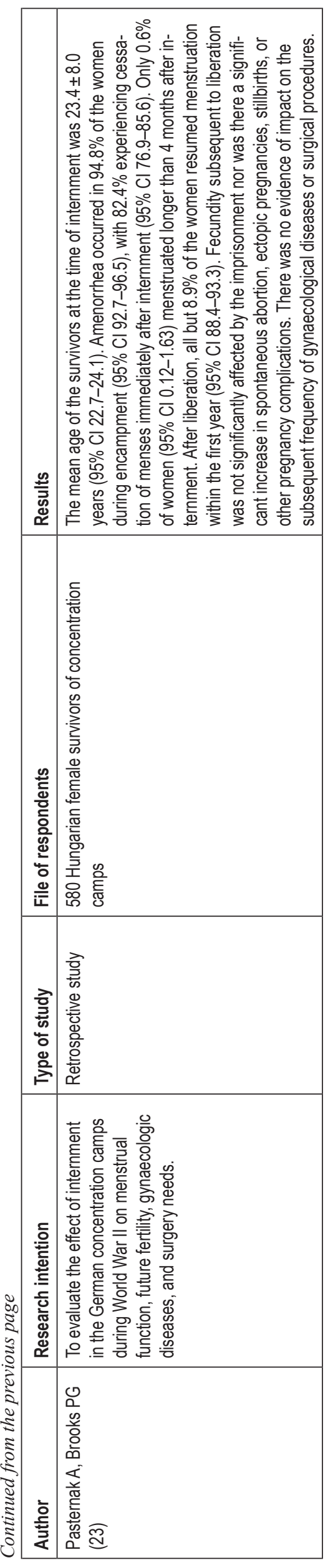

height were the domain of Dr. Mengele. Leg bone and muscle experimental operations were conducted on prisoners, with intentional infection of wounds and replacement of subducted material with a foreign body. The experiments aimed on study of bone, muscle and nerve recovery process with the purpose of solving problems in plastic surgery were extremely painful and caused permanent deformities (24-29).

These experiments might have led to serious health problems several years after the liberation. Staiman et al. in their case study describe a case of the patient who was diagnosed secondary huge malignant fibrous histiocytoma of the testis and spermatic cord 53 years after liberation.

The patient underwent in Auschwitz in 1943 the application of intratesticular injection with an unknown substance (30).

In most of Holocaust survivors post-traumatic stress disorder (PTSD) has been diagnosed in various time horizons since the end of WW II. Occurrence of wide spectrum of impacts on somatic and mental health, and their interconnection are mentioned among others by Sperling et al. in their study (31), which examined 80 Holocaust survivors suffering from PTSD based on medical documentation evaluation. The survivors were compared to another control group suffering PTSD caused by a trauma different from Holocaust. The data were analysed for presence of cardiovascular, gastrointestinal, and orthopaedic diseases developed in the time between the oldest and the most actual medical report. The analysis revealed higher incidence of myocardial infarction, chronic degenerative diseases, and cancer changes. No differences among groups were observed concerning either gender or age in the traumatization period, or age in the time of examination. The summary of the research presents the survivors as highly resistant patients. The resistance was an often-mentioned phenomenon in this research, mostly pointed to by respondents within the group of caring professionals and 2nd generation (31).

Mutual influence among somatic, mental and social health problems is suggested in the study of Israeli Ministry of Health carried out by Shemesh et al. (32). The study focused on assessment of emotional distress (ED), sleep disorders, chronic medical problems (civilization diseases occurrence such as hypertension, diabetes mellitus, myocardial infarction, cerebral artery stroke, or osteoporosis), social activities (such as concerts, lectures, sport, volunteering, and leisure activities), life contentment, and also several socio-demographic features of Holocaust survivors. The exposed group $(\mathrm{n}=896)$ formed Holocaust survivors (over 60 years of age) from the countries occupied by Nazis, and control group $(n=331)$ formed Jews (born either in the USA or Europe) without Holocaust experience. In the exposed group, considering socio-demographic features, the study points to higher divorce rate, life in isolation, and also higher education compared to the control group. Considering emotional distress intensity, statistically important difference was proved among the two groups (2.7 vs. 2.1, $\mathrm{p}<0.003)$. Apart from higher ED level in the exposed group, differences in relation to Holocaust survivors are obvious here as well. ED score in respondents who survived a Jewish ghetto is 2.8; a shelter 3.2; a work camp 3.1; and an extermination concentration camp is 2.9 . In survivors, there were also recorded more often sleep disorders, higher occurrence of chronic diseases, on the other hand in spending leisure time the control group displayed higher activity. The higher life contentment was displayed by the control group ( $<<0.04$ vs. $p<0.05$ ) (32). 


\section{CONCLUSION}

The study of effects of the Holocaust is an example of the fact how extreme mental and physical burden of an individual in the context of extreme population tragedy influence the health of the survivors. After the research in scientific databases and literary research, the effect of Holocaust experience in several body systems is obvious. The main subject of the research is the proof of the relationship between Holocaust experience and occurrence of cardiovascular symptoms, chronical degenerative diseases (especially osteoporosis) and cancer diseases. The scientists consider as a source mainly malnutrition in the period of prenatal development, childhood and adolescence, amenorrhea in girls and women during internment, physical punishments, hard work in unsuitable working conditions (dusty air, chemical substances, radiation influence, etc.), long-term stress and Nazi experiments in some Jewish ghettos and concentration camps to be the reason of such pathology. These findings showed higher rate of comorbidities on one hand, and lower mortality among people who survived the Holocaust on the other. This fact may be connected with combination of high level of medical literacy and unique resistance features of those who survived the Holocaust. These facts should by the focus of public health service activities, mainly in the field of prevention.

The number of Holocaust survivors in the Czech Republic cannot be determined exactly, as not every survivor feels the need to be a member of Jewish community or other organisation associating the affected individuals. It can be estimated that at the beginning of 2019 there were 500 Holocaust survivors in the Czech Republic (33).

The presented study results have led the authors to the question if the effects of the Holocaust in survivors who decided to stay in their homeland after World War II should be the same as in those who emigrated. Post-war life situation of Czech survivors was very specific. Totalitarian regime which lasted up to 1989 was not kind to Jewish citizens. The survivors and their families continued to live in insecurity and fear of the future. The health care and the social system of that time did not provide such persecuted people with any benefits in health care. In spite of that, a large number of those people lived to see high age, which leads the team of authors to consider how those people took care of their health after the war. This question is the subject of the following research in the future.

In conclusion, it should be reminded that Jewish communities and their health care and social committees play an essential role in care of this specific group of health and social care receivers. Each Jewish community provides social services in different range, some of them also health care. Health care and social care agencies associated with Jewish communities have existed in many countries and cities in the world. Their main purpose is to provide social, nursing or healthcare services to people with decreased selfsufficiency due to age, chronical disease, disability, or situation requiring assistance of another person. The agencies focus on the needs of seniors and have special approach to the needs of terror victims, Holocaust survivors or the victims of socialist violence, the personal aims are based on Jewish traditions and roots. The clients are enabled to maintain Jewish traditions and festivals (33-35).

The Foundation for Holocaust Victims, Claims Conference, Council for Nazi Victims, Jewish communities of particular cit- ies, Ministry of Health, and Ministry of Labour and Social Affairs participate in funding of the institutions. The care is provided with special focus on the needs of people surviving the Holocaust. The above-mentioned benefits and well-worked out systematic care can help the survivors to overcome the effects of huge pressure from their childhood or youth. However, the fact remains that not all survivors seek out this organised help. Healthcare professionals should bear these specifics of these seniors in mind and they should definitely be considered in health care provided to the survivors.

High age and vulnerability of survivors still living in Czechia and Slovakia encourages the last opportunity to study Holocaust impact on health. We assume that quantitative research design is not appropriate anymore and we recommend to focus on quality data collection through the method of life stories.

\section{Conflict of Interests}

None declared

\section{REFERENCES}

1. Lagus K, Polák K. The town behind bars. Prague: Naše vojsko; 1964. (In Czech.)

2. Cermáková K, Pilný J. The Nursing care about the holocaust survivors In: Jelínek T, Soukupová B, editors. Blank spots in holocaust research. Prague: Spolek akademiků Židů; 2014. p. 203-213. (In Czech.)

3. Pokorná A, et al. Nursing in geriatrics - The evaluation techniques. Prague: Grada; 2013. (In Czech.)

4. Pončová R. The care about holocaust survivors and their specifics [dissertation]. Prague: Charles University; 2010. (In Czech.)

5. Marečková J, Klugarová J, et al. Evidence-based health care: Healthcare based on stientific evidence. Olomouc: Palacký University Olomouc; 2015. (In Czech.)

6. Moher D, Liberati A, Tetzlaff J, Altman DG; PRISMA Group. Preferred reporting items for systematic reviews and meta-analyses: the PRISMA statement. J Clin Epidemiol. 2009;62(10):1006-12.

7. Fineout-Overholt E, Johnston L. Teaching EBP: a challenge for educators in the 21st century. Worldviews Evid Based Nurs. 2005;2(1):37-9.

8. Winick M, Osnos M. Hunger disease: studies by the Jewish physicians in the Warsaw Ghetto. New York: Wiley; 1979.

9. Roland CG. Courage under siege, starvation, disease and death in Ghetto Warsaw. Oxford: Oxford University Press; 1992.

10. Marcus EL, Menczel J. Higher prevalence of osteoporosis among female holocaust survivors. Osteoporos Int. 2007;18(11):1501-1506.

11. Weisz GM. Osteoporosis: a future public health problem for Israel? Medical and legal obligations. Isr Med Assoc J. 2017;19(4):203-206.

12. Weisz GM, Albury WR. Osteoporosis in survivors of early life starvation. Aust J Prim Health. 2013;19(1):3-6.

13. Mizrahi EH, Lubart E, Heymann A, Leibovitz A. Impact of the Holocaust on the rehabilitation outcome of older patients sustaining a hip fracture. Isr Med Assoc J. 2017 Apr; 19(4):207-10.

14. Yaari A, Eisenberg E, Adler R, Birkhan J. Chronic pain in Holocaust survivors. J Pain Symptom Manage. 1999;17(3):181-7.

15. Ablin JN, Cohen H, Eisinger M, Buskila D. Holocaust survivors: the pain behind the agony. Increased prevalence of fibromyalgia among Holocaust survivors. Clin Exp Rheumatol. 2010;28(6 Suppl 63):S51-6.

16. Bercovich E, Keinan-Boker L, Shasha SM. Long-term health effects in adults born during the Holocaust. Isr Med Assoc J. 2014;16(4):203-7.

17. Keinan-Boker L, Shasha-Lavsky H, Eilat-Zanani S, Edri-Shur A, Shasha SM. Chronic health conditions in Jewish Holocaust survivors born during World War II. Isr Med Assoc J. 2015;17(4):206-12.

18. Zamstein O, Biderman A, Sherf M, David RB, Dreiher J. Cardiovascular Morbidity and Risk Factors in Holocaust Survivors in Israel. J Am Geriatr Soc. 2018;66(9):1684-91.

19. Stermer E, Bar H, Levy N. Chronic functional gastrointestinal symptoms in Holocaust survivors. Am J Gastroenterol. 1991 Apr;86(4):417-22.

20. Sadetzki S, Chetrit A, Freedman LS, Hakak N, Barchana M, Catane R, et al. Cancer risk among Holocaust survivors in Israel - A nationwide study. Cancer. 2017 Sep 1;123(17):3335-45. 
21. David RB, Biderman A, Sherf M, Zamstein O, Dreiher J. Elevated cancer risk in Holocaust survivors residing in Israel: A retrospective cohort study. Eur J Cancer. 2018 May;95:85-92.

22. Tobias G, Zini A. Stress among Holocaust survivors and oral health. In: 6 th Meeting of the Pan European Region of the International Association for Dental Research; 2012 Sep 12-15; Helsinki, Finland.

23. Pasternak A, Brooks PG. The long-term effects of the Holocaust on the reproductive function of female survivors. J Minim Invasive Gynecol. 2007 Mar-Apr;14(2):211-7.

24. Mellanby K. Medical experiments on human beings in concentration camps in Nazi Germany. Br Med J. 1947 Jan 25;1(4490):148-50.

25. Benedict S, Georges JM. Nurses and the sterilization experiments of Auschwitz: a post-modernist perspective. Nurs Inq. 2006 Dec;13(4):27788

26. Muller-Hill B. Genetics of susceptibility to tuberculosis: Mengele's experiments in Auschwitz. Nat Rev Genet. 2001 Aug;2(8):631-4.

27. Schwalbová M. I lived the lives of others: from the memory of a doctor at Auschwitz. Zvolen: Klemo; 2001. (In Slovak.)

28. Baumslagová N. Murderous medicine: Nazi doctors, human experimentation, and typhus. Prague: Naše vojsko; 2013. (In Czech.)

29. Lang HJ. Women in block 10: medical experiments in Auschwitz. Prague: Ikar; 2014. (In Czech.)

30. Staiman VR, O’Toole KM, Rubin MA, Lowe FC. Giant malignant fibrous histiocytoma of the testis/spermatic cord: psychologic and possible etio- logic complications of unethical Nazi medical experimentation. Urology 1996 Dec;48(6):939-43.

31. SperlingW, Kreil S, Biermann T. Somatic diseases in child survivors of the Holocaust with posttraumatic stress disorder: a comparative study. J Nerv Ment Dis. 2012 May;200(5):423-8.

32. Shemesh AA, Kohn R, Radomislensky I, Brodsky J, Levav I. Emotional distress and other health-related dimensions among elderly survivors of the Shoa living in the community. Isr J Psychiatry Relat Sci. 2008;45(4):230-8

33. Federation of Jewish Communities inCR [Internet]. Prague: Federation of Jewish Communities in CR [cited 2020 Aug 1]. Available from: https:// www.fzo.cz/en/.

34. Claims Conference [Internet]. Tel Aviv: Claims Conference [cited 2020 Aug 1]. Available from: http://www.claimscon.org/.

35. The Jewish Community of Prague [Internet]. Prague: The Jewish Community of Prague [cited 2020 Aug 1]. Available from: https://www. kehilaprag.cz/en.

36. Barša P. Memory and genocide: reflections on politics and the Holocaust. Prague: Argo; 2011. 